\title{
Growth and Changes in the National Health Service Corps (NHSC) Workforce with the American Recovery and Reinvestment Act
}

\author{
Donald E. Pathman, MD, MPH, and Thomas R. Konrad, PhD
}

Background: From March 2009 through February 2011, the National Health Service Corps (NHSC) received a \$300 million supplement through the American Recovery and Reinvestment Act to grant more loan repayment awards to clinicians who agree to work in underserved areas. This study assesses how this unprecedented funding increase affected the size, composition, and location of the NHSC's workforce.

Methods: This was a descriptive, time-linked, observational study using NHSC administrative data. Main outcomes were growth and changes in disciplinary composition of the NHSC's workforce and in its rural/urban and state-to-state distribution.

Results: During the Recovery Act period, the NHSC's workforce increased by $156 \%$, from 3017 to 7713 clinicians. Mental health clinicians grew most numerically $(210 \%)$ and as a proportion of the NHSC's workforce (from $22.7 \%$ to $27.4 \%$ ). Primary care clinicians grew least and decreased as a proportion of the NHSC's workforce to $\mathbf{5 8 . 9 \%}$; dental health clinicians remained steady at approximately 13.5\%. Among individual disciplines, physicians decreased most as a component of the NHSC's overall workforce, from $38.6 \%$ to $26.7 \%$, whereas the proportion of nurse practitioners grew most, from $10.1 \%$ to $\mathbf{1 6 . 0 \%}$. Proportions of the NHSC's workforce serving in rural areas changed only modestly. NHSC clinician numbers grew most in states with the lowest NHSC clinician-to-poverty population ratios before the Recovery Act.

Conclusions: With Recovery Act funding, the NHSC's workforce become far larger and more diverse than ever and more evenly distributed across states. The NHSC should now set targets and be more deliberate in managing its growth across disciplines and where its clinicians serve. (J Am Board Fam Med 2012;25:723-733.)

Keywords: American Recovery and Reinvestment Act, Health Personnel, Health Policy, National Health Service Corps, Primary Health Care, Rural Health

The National Health Service Corps (NHSC) is the largest and most visible public program working to address the geographic maldistribution of the US

This article was externally peer reviewed.

Submitted 5 September 2011; revised 24 May 2012; accepted 29 May 2012.

From the Department of Family Medicine, and Cecil G. Sheps Center for Health Services Research, University of North Carolina, Chapel Hill (DEP); and University of North Carolina Institute on Aging, Chapel Hill (TRK).

Funding: none.

Conflict of interest: DEP serves on the NHSC's National Advisory Board, but this work was completed independently and does not necessarily reflect the views of the Board or the NHSC.

Corresponding author: Donald E. Pathman, MD, MPH, Department of Family Medicine, University of North Carolina, CB 7595, Chapel Hill, NC 27599 (E-mail: don pathman@unc.edu). health care workforce. ${ }^{1,2}$ Through scholarships to students and repaying the education loans of recent graduates, ${ }^{2}$ the NHSC makes work in community health centers and practices in other health professional service areas (HPSAs) financially possible and even attractive.

The NHSC was initially a program for primary care practitioners and dentists, ${ }^{3}$ but it now has broadened to offer loan repayment to mental health professionals and dental hygienists. During its 40-year history, the NHSC's in-the-field practitioner workforce has waxed and waned with fluctuations in its funding, sometimes to the frustration of needy communities. ${ }^{4,5}$ Its workforce peaked in 1986 with 3100 clinicians and peaked 
again in 2005 with 4602 clinicians,${ }^{6-8}$ but it has never come close to meeting the estimated need for providers within HPSAs, which totaled 31,623 clinicians as of early 2009. ${ }^{9}$ Supporters have long advocated for a larger NHSC. ${ }^{4,10-12}$

In February 2009, America's Recovery and Reinvestment Act ("Recovery Act") ${ }^{13}$ committed \$787 billion over 24 months to stimulate the US economy, create jobs, and build the nation's critical infrastructure. The Recovery Act designated \$300 million to expand the NHSC. ${ }^{13-15}$ With its recent regular annual federal appropriation funding of approximately $\$ 125$ million a year, the Recovery Act promised to add more than 4000 clinicians to the NHSC's workforce, ${ }^{14,16}$ by far the largest and most rapid growth in the NHSC's history.

The NHSC responded quickly. ${ }^{14,16,17}$ Able now to fill more positions, the NHSC extended loan repayment eligibility to practices within all HPSAs rather than to just a subset of the most needy. Federal and state recruitment staff helped newly eligible practices apply for NHSC site designation. ${ }^{16,18}$ The online application system for clinicians was streamlined and applications were now reviewed quickly and awards made continually rather than just once a year. Through these and other efforts, the NHSC was able to make the last of its awards with Recovery Act funds in February 2011, within the 24-month deadline. ${ }^{14}$

With the period of Recovery Act funding now past, we ask in this study how this unprecedented funding amount has affected the NHSC's workforce size, composition, and location. Did the NHSC's workforce change because some disciplines responded more vigorously than others to the short-notice expansion of loan repayment opportunities? Did broadened site eligibility and more available sites change the balance of the rural/ urban locations where the NHSC's clinicians serve or their distribution across the states? Clarifying how Recovery Act expansion changed the NHSC's workforce can be important because the NHSC continues to grow, with an additional approximately \$300 million supplement each year through 2017 under the Patient Protection and Affordable Care Act of 2010 (“Affordable Care Act”). ${ }^{19,20}$

\section{Methods}

We obtained data from the Bureau of Clinician Recruitment and Service's Management Informa- tion System Solution (BMISS), the NHCS's administrative database that contains detailed information about its clinicians and sites. We received raw data for every clinician actively serving in the NHSC's Scholarship and Loan Repayment Programs on the last day of each federal calendar quarter from September 30, 2007, through December 31, 2010, and on February 28, 2011, approximately 2 weeks after the last NHSC contracts were made with Recovery Act funding. The BMISS database does not contain information about clinicians serving in the NHSC's joint state-federal funded State Loan Repayment Program; hence, these several hundred clinicians are not included in this report. ${ }^{14}$

The file we received contained an indicator of the program in which each clinician was serving (Scholarship vs Loan Repayment), information about clinicians' clinical disciplines and specialties, and location information for each clinician's principal site of service as of the last date of each quarter, including city, state, ZIP code, and a rural/ urban indicator. The file contained information for 68,662 clinician-quarters for 10,886 distinct clinicians.

Because the rural-urban indicator in the BMISS database is based on self-reported information provided by clinic staff when they apply to be designated as an NHSC site, we assessed it against a more uniform and accepted subcounty rural-urban classification, specifically, the ZIP code approximation of census tract-based Rural-Urban Commuting Area (RUCA) codes dichotomized in standard fashion to urban (codes 1 to 3 ) and rural (codes 4 to 10) areas. ${ }^{21,22}$ For sites located within the continental United States and Hawaii, rural/urban classifications based on RUCA codes and sites' self-reports differed for $23.0 \%$ of clinician-quarters, with self-reports yielding approximately $23 \%$ higher rural site proportions overall. We used the RUCAbased rural-urban classification in all analyses except for the 447 clinician-quarters in which clinicians were serving in American territories, for which RUCA codes are unavailable.

\section{Analysis}

Because the NHSC assigned clinicians to either Recovery Act or regular annual appropriation funds without regard to characteristics of clinicians or sites (ie, the funds are used interchangeably), we included both groups in our analyses. Analyses are 
descriptive, characterizing NHSC clinician numbers in the Loan Repayment and Scholarship Programs and within individual and groups of disciplines both before and after the Recovery Act period.

Numbers of NHSC clinicians in rural and urban areas before and after Recovery Act funding are presented using the ZIP code-based RUCA rural-urban classification. We describe the variation in numbers of NHSC clinicians across states before Recovery act funding, as well as the variation in growth of NHSC clinicians across states over the 2-year Recovery Act period. We normalized state differences in NHSC clinician numbers by assessing them against the number of individuals living below the federal poverty level in each state. ${ }^{23}$

Analyses were conducted using SPSS Statistics version 18.0 (IBM, Somers, NY) and Microsoft Excel 2010 (Redmond, WA). This study was approved by the Public Health Nursing Institutional Review Board of the University of North Carolina at Chapel Hill on February 17, 2011.

\section{Results}

\section{Growth of the NHSC Workforce}

The NHSC's overall workforce remained essentially unchanged in size during the 18 months before March 2009, the start of Recovery Act period, but from then on numbers steadily increased (Figure 1). From March 2009 through February 2011, numbers of total clinicians serving in the NHSC rose from 3017 to 7713 , an increase of 4696 clinicians, or a $156 \%$ gain (Table 1 ).

The entire growth in the NHSC's overall workforce from March 2009 to February 2011 was because of growth in its Loan Repayment Program, which grew 191\% (Table 1). Numbers of clinicians serving in the Scholarship Program's workforce remained essentially unchanged during the Recovery Act period; its expanded student numbers under Recovery Act support will not enter the NHSC's clinician workforce until after these students graduate in coming years.

\section{Changes in Discipline and Specialty Composition Loan Repayment Program}

Numbers in the Loan Repayment Program's primary care, mental health, and dental health disciplines all roughly doubled during the Recovery Act period, so there was little change in the relative proportions of the 3 within the program: $58 \%$ primary care, $28 \%$ mental health, and $14 \%$ dental health (Table 1). However, within the primary care group, physician numbers grew far less $(114 \%)$ over the 2 -year period than did the growth in nurse practitioners (367\%), physician assistants (199\%), and nurse midwives (175\%). Physicians' proportion of all loan repayers dropped from $31.3 \%$ to $23.1 \%$. Among mental health disciplines, growth was greatest for licensed professional counselors (389\%), and among the NHSC's larger mental health groups,

Figure 1. Growth in the National Health Service Corps' active clinician workforce in the Loan Repayment and Scholarship Programs, September 2007 through February 2011. (Data from the US Bureau of Clinician Recruitment and Service's Management Information System Solution.)

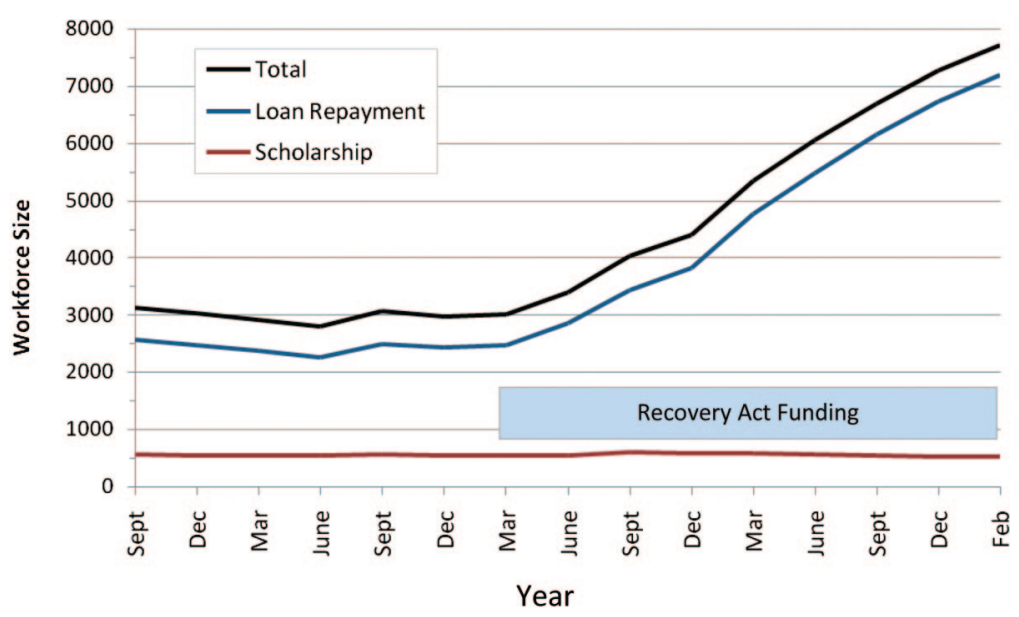


Table 1. Change in the Number of Clinicians of Each Discipline in the National Health Service Corps (NHSC) Loan Repayment and Scholarship Programs during the American Recovery and Reinvestment Act Funding Period

\begin{tabular}{|c|c|c|c|}
\hline Clinicians by Program & March 30, 2009* & February $28,2011^{*}$ & Increase in Numbers (\%) \\
\hline \multicolumn{4}{|l|}{ Loan Repayment Program } \\
\hline Primary care total & $1449(58.6)$ & $4095(57.0)$ & 183 \\
\hline Physicians & $774(31.3)$ & $1660(23.1)$ & 114 \\
\hline Nurse practitioners & $258(10.4)$ & $1205(16.8)$ & 367 \\
\hline Physician assistants & $353(14.3)$ & $1054(14.7)$ & 199 \\
\hline Nurse midwives & $64(2.6)$ & $176(2.4)$ & 175 \\
\hline Dental total & $341(13.8)$ & 975 (13.6) & 186 \\
\hline Dentists & $310(12.5)$ & $808(11.2)$ & 161 \\
\hline Dental hygienists & $31(1.3)$ & $167(2.3)$ & 439 \\
\hline Mental health total & $684(27.6)$ & $2117(29.4)$ & 210 \\
\hline Clinical psychologists & $329(13.3)$ & $752(10.5)$ & 129 \\
\hline Clinical social workers & $177(7.2)$ & $620(8.6)$ & 250 \\
\hline Licensed professional counselors & $130(5.3)$ & $636(8.8)$ & 389 \\
\hline Marriage and family therapists & $39(1.6)$ & $93(1.3)$ & 138 \\
\hline Psychiatric nurse specialists & $9(0.4)$ & $16(0.2)$ & 78 \\
\hline Loan Repayment Program total & $2474(100)$ & $7187(100)$ & 191 \\
\hline \multicolumn{4}{|l|}{ Scholarship Program } \\
\hline Primary Care Total & $479(88.2)$ & $449(85.4)$ & -6 \\
\hline Physicians & $391(72.0)$ & $396(75.3)$ & 1 \\
\hline Nurse practitioners & $47(8.7)$ & $28(5.3)$ & -40 \\
\hline Physician assistants & $29(5.3)$ & $17(3.2)$ & -41 \\
\hline Nurse midwives & $12(2.2)$ & $8(1.5)$ & -33 \\
\hline Dental total & $64(11.8)$ & $77(14.6)$ & 20 \\
\hline Dentists & $64(11.8)$ & 77 (14.6) & 20 \\
\hline Scholarship Program total & $543(100)$ & $526(100)$ & -3 \\
\hline Combined/total NHSC workforce (n) & 3017 & 7713 & 156 \\
\hline
\end{tabular}

Data from the US Bureau of Clinician Recruitment and Service's Management Information System Solution.

*Data provided as $\mathrm{n}$ (\% of total in program).

growth was least for clinical psychologists $(129 \%)$.

\section{Scholarship Program}

Within the essentially unchanged size of the Scholarship Program workforce, there was moderate growth in dentist numbers (20\%), negligible growth in physician numbers $(1 \%)$, and a one-third or greater decrease in numbers of physician assistants, nurse practitioners, and certified nurse midwives (Table 1).

\section{NHSC's Overall Workforce}

Primary care clinicians increased from 1928 to 4544 in number but their proportion of all NHSC clinicians decreased, from $63.9 \%$ to $58.9 \%$ (Figure 2; Table 1). The mental health component of the NHSC's workforce grew fastest proportionately, from 684 to 2117 clinicians, thereby increasing from $22.7 \%$ to $27.4 \%$ of the NHSC's total workforce. The dental health component of the NHSC's overall clinician workforce changed only slightly, from $13.4 \%$ to $13.6 \%$.

Among individual disciplines, physicians decreased most as a component of the NHSC's overall workforce, dropping from $38.6 \%$ to $26.7 \%$. Greatest growth was seen in nurse practitioners, who increased from $10.1 \%$ to $16.0 \%$ of all NHSC clinicians.

The relative numbers among the NHSC's 5 eligible physician specialties did not change significantly from March 2009 to February 2011. The percentage of all physicians who were family physicians changed from $53.4 \%$ to $56.0 \%$; pediatricians changed from $16.2 \%$ to $16.6 \%$; general internists changed from $12.9 \%$ to $10.7 \%$; obstetrician/gynecologists changed from $10.3 \%$ to 
Figure 2. Growth in the National Health Service Corps' active clinician workforce by discipline group, September 2007 through February 2011. NP, nurse practitioner; PA, physician assistant; CNM, certified nurse midwife. (Data from the US Bureau of Clinician Recruitment and Service's Management Information System Solution.)

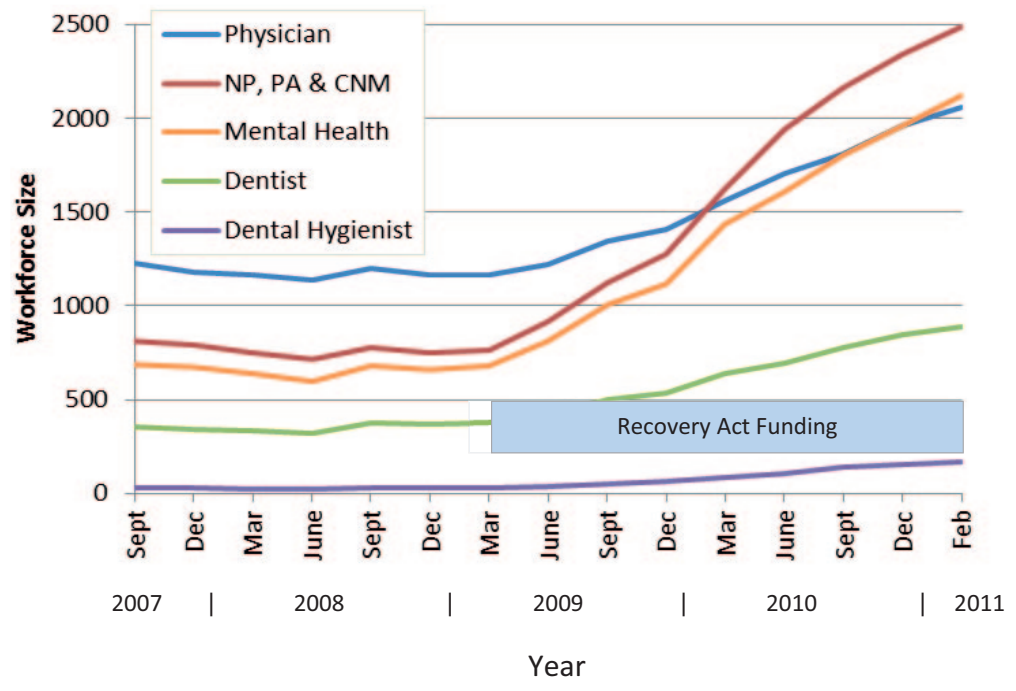

$9.1 \%$; and psychiatrists changed from $7.2 \%$ to $7.5 \%$.

\section{Changes in Rural-Urban Distribution}

The Recovery Act period saw little change in the rural versus urban distribution of the NHSC's workforce. Before the Recovery Act period, 1349 of the NHSC's 3017 clinicians (44.7\%) were serving in rural areas as defined by the RUCA classification, and as of February 2011, 3236 of 7713 clinicians $(42.0 \%)$ were serving in rural areas. Similarly, the proportion of NHSC clinicians that worked in the very smallest towns-those with a population $<2500$ (RUCA codes 7 through 10)-decreased modestly from $27.0 \%$ (810 of 2999$)$ to $23.5 \%$ (1807 of 7676).

\section{Changes in State Location}

Before the Recovery Act, the number of NHSC clinicians who were serving in each state varied by more than 100-fold (Table 2). With Recovery Act funding, NHSC clinician numbers increased within every state, but the percentage of growth varied significantly across states (Table 2, Figure 3).

At the beginning of the Recovery Act period, states also varied greatly in their numbers of NHSC clinicians relative to the size of their poor populations, with rates varying from 0.63 to 62.9 NHSC clinicians per 100,000 people in poverty (Table 3). We sorted states into lowest to highest quartiles in terms of their pre-Recovery Act numbers of NHSC clinicians per 100,000 population below poverty and found that growth in NHSC clinician numbers was $291 \%$ in states with the fewest NHSC clinicians per 100,000 people below poverty before the Recovery Act versus a more modest $111 \%$ growth in states with the most NHSC clinicians per 100,000 people below poverty initially (Table 3).

As of March 2009 and before Recovery Act growth, primary care clinicians were the largest component of the NHSC's workforce in all states except Minnesota and Wyoming, where they were outnumbered by mental health clinicians. As of February 2011, mental health clinicians outnumbered primary care clinicians in 6 states.

\section{Discussion}

Through the Recovery Act, the NHSC workforce grew to 2.5 times its prior size to 7713 clinicians and became far larger than it ever had been. It is estimated that the number of people receiving care each year from NHSC clinicians increased from 4 million to 9 million during this period. ${ }^{24}$ Nevertheless, even when the NHSC reached more than 10,000 clinicians in 2011 with additional Affordable Care Act funding, ${ }^{19}$ its workforce still met less than one third of the need for clinicians in HPSAs, estimated at 34,000 as of mid- $2011 .^{25}$ 
Table 2. Growth in Numbers of National Health Service Corps Clinicians in Each US State and the US Territories during the American Recovery and Reinvestment Act Funding Period

\begin{tabular}{|c|c|c|c|c|c|c|c|c|c|}
\hline & \multicolumn{4}{|c|}{ March 2009} & \multicolumn{4}{|c|}{ February 2011} & \multirow[b]{2}{*}{$\begin{array}{c}\text { Total Gain } \\
(\mathrm{n}(\%))\end{array}$} \\
\hline & $\begin{array}{l}\text { Primary } \\
\text { Care }\end{array}$ & $\begin{array}{l}\text { Dental } \\
\text { Health }\end{array}$ & $\begin{array}{l}\text { Mental } \\
\text { Health }\end{array}$ & Total & $\begin{array}{l}\text { Primary } \\
\text { Care }\end{array}$ & $\begin{array}{l}\text { Dental } \\
\text { Health }\end{array}$ & $\begin{array}{l}\text { Mental } \\
\text { Health }\end{array}$ & Total & \\
\hline US Total & 1928 & 405 & 684 & 3017 & 4544 & 1052 & 2117 & 7713 & $4696(156)$ \\
\hline Alabama & 37 & 7 & 7 & 51 & 72 & 15 & 22 & 109 & $58(114)$ \\
\hline Alaska & 17 & 1 & 4 & 22 & 39 & 5 & 21 & 65 & $43(195)$ \\
\hline Arizona & 58 & 9 & 28 & 95 & 128 & 28 & 37 & 193 & $98(103)$ \\
\hline Arkansas & 8 & 1 & 33 & 42 & 39 & 5 & 37 & 81 & $39(93)$ \\
\hline California & 147 & 40 & 112 & 299 & 432 & 104 & 272 & 808 & $509(170)$ \\
\hline Colorado & 58 & 5 & 19 & 82 & 147 & 20 & 80 & 247 & $165(201)$ \\
\hline Connecticut & 25 & 9 & 1 & 35 & 59 & 26 & 32 & 117 & $82(234)$ \\
\hline Delaware & 10 & 0 & 0 & 10 & 14 & 0 & 1 & 15 & $5(50)$ \\
\hline DC & 61 & 5 & 0 & 66 & 60 & 5 & 6 & 71 & $5(8)$ \\
\hline Florida & 131 & 24 & 9 & 164 & 203 & 43 & 47 & 293 & $129(79)$ \\
\hline Georgia & 41 & 6 & 3 & 50 & 100 & 22 & 38 & 160 & $110(220)$ \\
\hline Hawaii & 12 & 5 & 8 & 25 & 24 & 9 & 15 & 48 & $23(92)$ \\
\hline Idaho & 44 & 10 & 19 & 73 & 95 & 19 & 64 & 178 & $105(144)$ \\
\hline Illinois & 106 & 11 & 24 & 141 & 251 & 40 & 96 & 387 & $246(174)$ \\
\hline Indiana & 29 & 4 & 21 & 54 & 54 & 11 & 50 & 115 & $61(113)$ \\
\hline Iowa & 19 & 5 & 10 & 25 & 38 & 20 & 34 & 92 & $67(268)$ \\
\hline Kansas & 20 & 7 & 16 & 43 & 57 & 17 & 24 & 98 & $55(128)$ \\
\hline Kentucky & 23 & 1 & 15 & 39 & 70 & 14 & 52 & 136 & 97 (249) \\
\hline Louisiana & 26 & 8 & 8 & 42 & 65 & 28 & 34 & 127 & $85(202)$ \\
\hline Maine & 14 & 6 & 9 & 29 & 63 & 22 & 16 & 101 & $72(248)$ \\
\hline Maryland & 33 & 1 & 6 & 40 & 66 & 4 & 17 & 87 & 47 (118) \\
\hline Massachusetts & 72 & 6 & 17 & 95 & 153 & 20 & 52 & 225 & $130(137)$ \\
\hline Michigan & 57 & 15 & 11 & 83 & 177 & 31 & 43 & 251 & $168(202)$ \\
\hline Minnesota & 18 & 0 & 38 & 56 & 57 & 15 & 102 & 174 & $118(211)$ \\
\hline Mississippi & 20 & 5 & 4 & 29 & 57 & 12 & 24 & 93 & $64(221)$ \\
\hline Missouri & 71 & 14 & 49 & 134 & 138 & 48 & 155 & 341 & 207 (154) \\
\hline Montana & 38 & 6 & 23 & 67 & 66 & 15 & 63 & 144 & $77(115)$ \\
\hline Nebraska & 5 & 4 & 5 & 14 & 36 & 8 & 23 & 67 & $53(379)$ \\
\hline Nevada & 10 & 0 & 2 & 12 & 14 & 3 & 3 & 20 & $8(67)$ \\
\hline New Hampshire & 2 & 1 & 3 & 6 & 14 & 3 & 22 & 39 & $33(550)$ \\
\hline New Jersey & 4 & 1 & 0 & 5 & 20 & 8 & 4 & 32 & $27(540)$ \\
\hline New Mexico & 48 & 14 & 15 & 77 & 73 & 23 & 29 & 125 & $48(62)$ \\
\hline New York & 115 & 42 & 17 & 174 & 279 & 50 & 68 & 397 & $223(128)$ \\
\hline North Carolina & 46 & 10 & 10 & 66 & 115 & 26 & 43 & 184 & $118(179)$ \\
\hline North Dakota & 13 & 0 & 8 & 21 & 21 & 4 & 19 & 44 & $23(110)$ \\
\hline Ohio & 29 & 12 & 10 & 51 & 79 & 19 & 32 & 130 & $79(155)$ \\
\hline Oklahoma & 15 & 5 & 11 & 31 & 45 & 15 & 46 & 106 & $75(242)$ \\
\hline Oregon & 28 & 16 & 3 & 47 & 90 & 23 & 26 & 145 & 98 (209) \\
\hline Pennsylvania & 39 & 8 & 3 & 51 & 120 & 35 & 36 & 191 & $140(275)$ \\
\hline Rhode Island & 11 & 9 & 1 & 21 & 18 & 7 & 8 & 33 & $12(057)$ \\
\hline South Carolina & 47 & 5 & 1 & 53 & 84 & 10 & 23 & 117 & $64(121)$ \\
\hline South Dakota & 9 & 1 & 5 & 15 & 19 & 9 & 21 & 49 & $34(227)$ \\
\hline Tennessee & 59 & 11 & 18 & 88 & 138 & 22 & 31 & 191 & $103(117)$ \\
\hline Texas & 78 & 24 & 3 & 105 & 173 & 53 & 35 & 261 & $156(149)$ \\
\hline Utah & 36 & 4 & 18 & 58 & 68 & 14 & 29 & 111 & $53(91)$ \\
\hline Vermont & 0 & 0 & 2 & 2 & 11 & 2 & 10 & 23 & $21(1050)$ \\
\hline
\end{tabular}

Continued 


\begin{tabular}{|c|c|c|c|c|c|c|c|c|c|}
\hline & \multicolumn{4}{|c|}{ March 2009} & \multicolumn{4}{|c|}{ February 2011} & \multirow[b]{2}{*}{$\begin{array}{l}\text { Total Gain } \\
\text { (n (\%)) }\end{array}$} \\
\hline & $\begin{array}{l}\text { Primary } \\
\text { Care }\end{array}$ & $\begin{array}{l}\text { Dental } \\
\text { Health }\end{array}$ & $\begin{array}{l}\text { Mental } \\
\text { Health }\end{array}$ & Total & $\begin{array}{l}\text { Primary } \\
\text { Care }\end{array}$ & $\begin{array}{l}\text { Dental } \\
\text { Health }\end{array}$ & $\begin{array}{l}\text { Mental } \\
\text { Health }\end{array}$ & Total & \\
\hline Virginia & 20 & 5 & 2 & 27 & 49 & 16 & 25 & 90 & $63(233)$ \\
\hline Washington & 43 & 13 & 9 & 65 & 167 & 50 & 55 & 272 & $207(318)$ \\
\hline West Virginia & 17 & 1 & 1 & 19 & 77 & 11 & 6 & 94 & $75(395)$ \\
\hline Wisconsin & 42 & 6 & 20 & 68 & 67 & 33 & 50 & 150 & $82(121)$ \\
\hline Wyoming & 9 & 1 & 22 & 32 & 10 & 3 & 36 & 49 & $17(053)$ \\
\hline $\begin{array}{l}\text { US territories in South } \\
\text { Pacific and Caribbean* }\end{array}$ & 17 & 0 & 1 & 18 & 33 & 1 & 3 & 37 & $21(131)$ \\
\hline
\end{tabular}

Data from the US Bureau of Clinician Recruitment and Service's Management Information System Solution.

*US territories in Caribbean include Puerto Rico and the US Virgin Islands. US territories in the South Pacific include Guam, American Samoa, Federated States of Micronesia, and Northern Marianas.

The NHSC responded quickly and successfully to make more than 4000 new awards with Recovery Act funds. Its growth was assisted by expanded program flexibility from Congress, ${ }^{13,26}$ guidance from its National Advisory Council and others, ${ }^{26}$ and the recruitment efforts of states' primary care offices and other recruiters. ${ }^{24-28}$ The Loan Repayment Program added a long-sought half-time service option and increased maximum loan repayment amounts. ${ }^{12,23,29}$ NHSC Regional Office staff

Figure 3. Map of percentage and numerical growth in National Health Service Corps' clinicians in each US state during the American Recovery and Reinvestment Act funding period, March 2009 through February 2011. (Data from the US Bureau of Clinician Recruitment and Service's Management Information System Solution.)

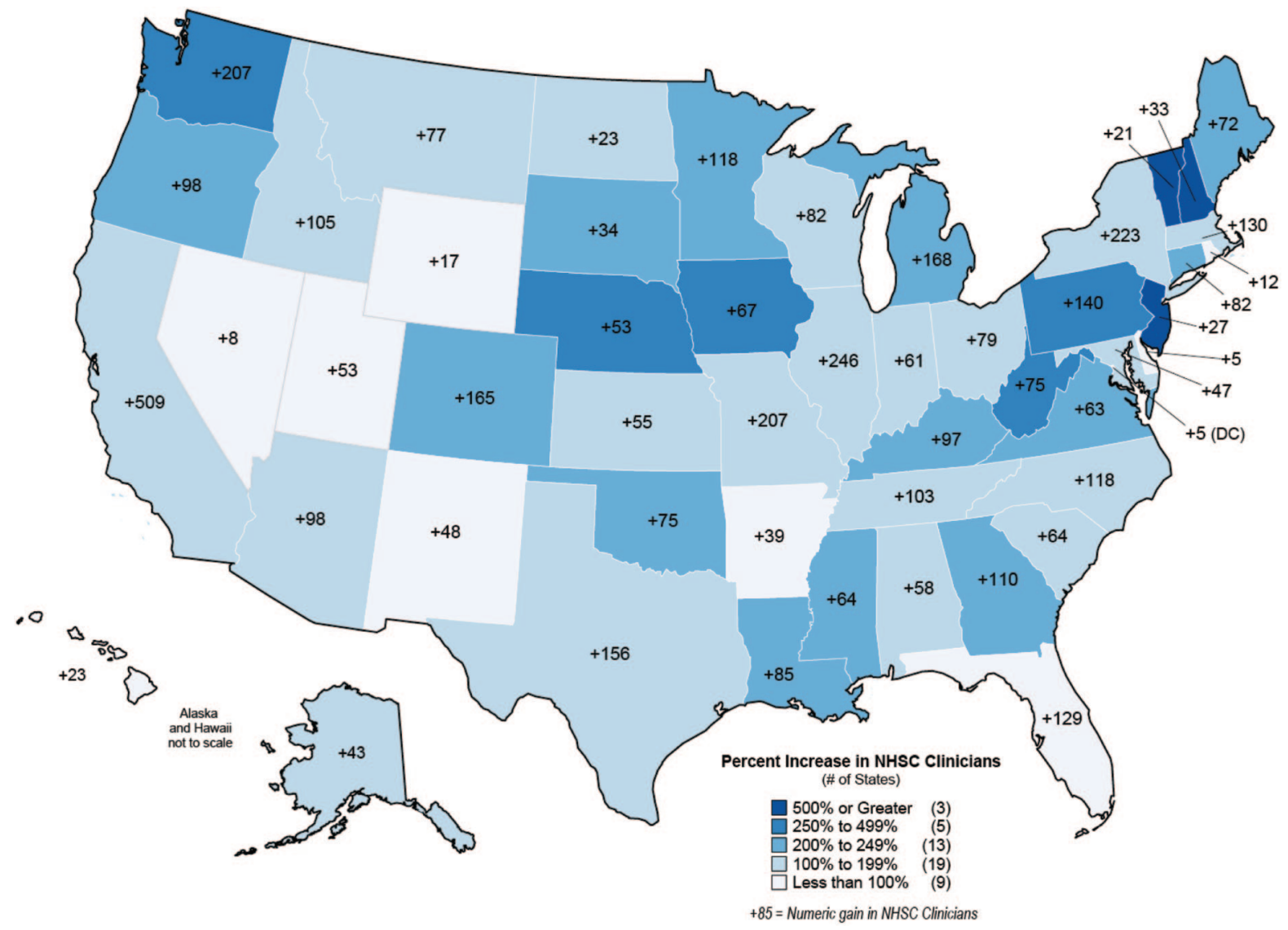


Table 3. Percentage Growth in States' Total National Health Service Corps (NHSC) Clinician Numbers during the American Recovery and Reinvestment Act Period: Relationship to Baseline Number of Corps Loan Repayment Clinicians per 100,000 Population Below Poverty*

\begin{tabular}{|c|c|c|c|c|}
\hline State quartile at baseline & States (n) & $\begin{array}{l}\text { States' Baseline NHSC Clinicians per } \\
\text { 100,000 Population Below Poverty }\end{array}$ & $\begin{array}{l}\text { States' Growth in NHSC Clinicians } \\
\text { During Recovery Act Period (mean \%) }\end{array}$ & SD \\
\hline Lowest quartile $^{\dagger}$ & 13 & $0.63-5.36$ & $291 \%$ & 253 \\
\hline Second lowest quartile ${ }^{\ddagger}$ & 13 & $5.49-7.96$ & $210 \%$ & 146 \\
\hline Second highest quartile & 13 & $8.08-14.50$ & $172 \%$ & 71 \\
\hline Highest quartile ${ }^{\mathbb{I}}$ & 12 & $15.78-62.92$ & $111 \%$ & 67 \\
\hline All states' average & 51 & $0.63-62.92$ & $197 \%$ & 164 \\
\hline
\end{tabular}

$P=.041$

*Baseline NHSC clinician numbers as of March 30, 2009; growth in NHSC numbers assessed between March 30, 2009, and February 28, 2011. Data from the US Bureau of Clinician Recruitment and Service's Management Information System Solution.

${ }^{\dagger}$ Lowest quartile: Georgia, Kentucky, Michigan, Mississippi, Nevada, New Jersey, North Carolina, Ohio, Oklahoma, Pennsylvania, Texas, Vermont, Virginia.

${ }^{\ddagger}$ Second lowest quartile: Alabama, Arkansas, California, Florida, Indiana, Iowa, Louisiana, Maryland, Nebraska, New Hampshire, New York, South Carolina, West Virginia.

${ }^{\S}$ Second highest quartile: Arizona, Colorado, Connecticut, Delaware, Illinois, Kansas, Massachusetts, Minnesota, Oregon, South Dakota, Tennessee, Washington, Wisconsin.

"Highest quartile: Alaska, District of Columbia, Hawaii, Idaho, Maine, Missouri, Montana, New Mexico, North Dakota, Rhode Island, Utah, Wyoming.

now make routine visits to NHSC sites. ${ }^{30}$ Faced with the challenge and opportunity of rapid expansion, the NHSC is building the culture and system of supports required for a large, nationally dispersed, and diverse workforce of over 10,000 young clinicians.

The clinician composition of the NHSC's workforce changed during its Recovery Act growth. Primary care's contribution decreased from $64 \%$ to $59 \%$, specifically because physician growth did not keep pace with other health professions. Physicians' contribution to the NHSC's overall workforce was more than $50 \%$ in the late $1990 \mathrm{~s}^{6}$ and had decreased to $39 \%$ by March 2009, then decreased further, to $27 \%$, by February 2011 to become a smaller part of the NHSC's workforce than at any point in its history.

As of 2000, fewer than 200 mental health professionals were serving in the NHSC. ${ }^{12}$ After deliberate efforts to diversify the NHSC's workforce, mental health clinicians had grown to $23 \%$ of the NHSC's workforce by March 2009 and then grew to $27 \%$ during the Recovery Act period. The dental component of the NHSC workforce remained unchanged (at about 14\%) during the Recovery Act years.

The NHSC's priority during the Recovery Act period was to recruit clinicians quickly to build the size of its workforce. No specific goals were set for the relative size of the NHSC's primary care, men- tal health, and dental health components or for specific disciplines. Growth for each discipline occurred independently and resulted from how appealing its clinicians found the NHSC's expanded loan repayment opportunities and available practice sites. We note that response was more vigorous from disciplines with lower average incomes, including licensed professional counselors among mental health practitioners, dental hygienists among dental health practitioners, and nurse practitioners among primary care practitioners. For these disciplines, $\$ 50,000$ in loan repayment for an initial 2-year commitment means more and is a stronger enticement than it is for higher-income clinical psychologists, dentists, and physicians, who responded well, but not as well, in the NHSC's expansion.

With a still great unmet need for clinicians of all fields within HPSAs, any and all growth of any of the NHSC's disciplines is a good thing. Nevertheless, growth for such an important health workforce program should be guided by some notion of size targets for its various participating disciplines. For a program that views population health needs broadly and values interdisciplinary care, there may be no simple or noncontentious way to set size targets for individual or groups of disciplines. One reasonable approach would be to give preference to disciplines that are hardest to recruit into needy areas without external incentives. ${ }^{31}$ Another rea- 
sonable approach is to target disciplines that demonstrate best outcomes with loan repayment and scholarships, such as longest retention. Another advocated approach is to aim for a balanced workforce that meets the same percentage of the estimated shortage for clinicians within primary care, dental health, and mental health HPSAs. ${ }^{12}$ With 7713 clinicians able to provide $22.8 \%$ of the 33,759 clinicians of all types needed within HPSAs as of early May 2011, ${ }^{25}$ a balanced allocation would have the NHSC meet $22.8 \%$ of the 17,588 clinician shortages in primary care HPSAs, $22.8 \%$ of the 6142 clinician shortages in mental health HPSAs, and $22.8 \%$ of the 10,029 clinician shortages in dental HPSAs. Against these numbers, the NHSC workforce after the Recovery Act period has 54\% too few dental health clinicians, $51 \%$ too many mental health clinicians, and $13 \%$ too many primary care clinicians.

In the fall of 2010, the NHSC announced an increase in the maximum loan repayment amount for all disciplines, from $\$ 50,000$ to $\$ 60,000$ for an initial 2-year contract. ${ }^{1}$ If a goal was set to increase the numbers of dentists, physicians, other specific disciplines, or all three, then it would be preferable to selectively increase loan repayment amounts for these groups only. Such a 2-tier loan repayment amount structure is used by the loan repayment programs of some states. ${ }^{32,33}$

Able to place more clinicians with its Recovery Act dollars, the NHSC no longer needed to set a HPSA score floor requirement and therefore made clinics in all HPSAs eligible to apply to become NHSC sites. This led to roughly a doubling of NHSC sites to more than $10,000 .{ }^{18}$ Despite this expansion of service site opportunities, we found only modest changes in the rural-urban balance of the NHSC's workforce during the Recovery Act period, with the rural proportion decreasing from $44.7 \%$ to $42.0 \%$. But with more than $50 \%$ of the clinician shortages in primary care, dental, and mental health HPSAs being within rural areas, ${ }^{25}$ it seems that the NHSC's workforce remains somewhat over-allocated to urban settings. The NHSC relies on clinics' self-designations of their rural versus urban location and therefore views its workforce as being slightly more than half rural. ${ }^{34}$ Clinics' self-designations may, in fact, better reflect the "ruralness" of their settings than official, standardized rural-urban designations. But the opposite also could be true, and self-designations are surely less uniform. The rural-urban distribution of the NHSC's workforce deserves further reevaluation so that it can be accurately and confidently understood and, if needed, adjusted in the future.

More significant were the changes in the states where NHSC clinicians were serving. Recovery Act growth yielded a more even distribution of NHSC clinicians across states relative to their need. We suspect this was a positive consequence of the elimination of the HPSA score threshold for site eligibility, which had previously disadvantaged some states whose needy populations were constituted and distributed in ways that yielded lower HPSA scores based on the one-size-fits-all HPSA formula.

\section{Limitations}

Our documented 2474 loan repayors and 543 Scholars in the NHSC as of February 2009 are similar to the numbers reported by HRSA for early June $2009^{35}$ but are somewhat fewer than figures before the Recovery Act reported elsewhere. ${ }^{36}$ Figures from these various sources differ from each other and from the numbers we report because calculations for each are for somewhat different dates, rely on somewhat different data sources, and sometimes track different clinician groups (eg, only some include participants of the NHSC's State Loan Repayment Program).

We reported psychiatrists and psychiatric nurse practitioners within the primary care component of the NHSC's workforce. If instead we had included them as mental health practitioners, the size of the NHSC's mental health component would have been calculated larger and its primary care component smaller.

This study documents only the effects of Recovery Act funds on the NHSC's workforce during the initial 2 years when funds were allocated. Many of the more than 4000 clinicians awarded Loan Repayment with Recovery Act funds will continue to contribute to NHSC workforce figures through 2012 and early 2013, and some of the 255 students awarded scholarships with Recovery Act funds will remain in the NHSC's workforce through as late as 2021. Furthermore, the figures we report do not include the estimated 330 clinicians awarded loan repayment with Recovery Act funds through states' NHSC State Loan Repayment Programs. ${ }^{14}$ 


\section{Conclusions}

Educational scholarship and loan repayment incentives cannot, on their own, completely right the maldistribution of the US health care workforce when there are nationwide shortages for most disciplines and many attractive job and salary opportunities available in nonunderserved areas. Nevertheless, Recovery Act funding has enabled the NHSC to now deploy a workforce of sufficient size and disciplinary diversity to make a sizable dent in the clinician needs of shortage areas.

Having updated its programs and operations and having successfully weathered the turbulence of rapid growth, the NHSC is now well constituted to face the demands of managing its larger workforce. But with more efficient operations and a record number of clinician applicants this year, it is important now for the NHSC to strategically target its allocation of new awards so that its workforce is constituted to make the greatest possible contribution to health and health care access in needy communities. This will require setting targets for the disciplinary composition and location of the NHSC workforce and then adjusting outreach activities, contract terms and incentives, and clinician and site selection criteria to favor targeted disciplines and communities. In the current 2012 Loan Repayment application cycle, the NHSC for the first time tiered its payment amounts to incentivize sites with higher HPSA scores. ${ }^{37}$ The NHSC should consider similarly tiering its payment amounts to proportionally reflect the sizable differences in disciplines' debts and incomes and to incent disciplines that are falling shortest of communities' and the NHSC's recruitment targets.

The authors thank Ms. Katie Gaul at the University of North Carolina's Cecil G. Sheps Center for Health Services Research for creating this article's map.

\section{References}

1. National Health Service Corps [homepage]. Available from: http://www.nhsc.hrsa.gov/. Accessed May 7, 2012.

2. Mullan F. The National Health Service Corps and health personnel innovations: beyond poorhouse medicine. In: Sidel VW, Sidel R, eds. Reforming medicine: lessons from the last quarter century. New York, NY: Pantheon Books; 1984.
3. Porterfield DS, Konrad TR, Leysieffer K, et al. Caring for the underserved: current practice of alumni of the National Health Service Corps. J Health Care Poor Underserved 2003;14:256-71.

4. National Health Service Corps Stakeholders Association. Untitled letter to Senators Daniel Inouye, Tom Harkin, and Thad Cochran. June 18, 2009. Available from: http://www.ama-assn.org/resources/ doc/mss/nhsc-funding.pdf. Accessed May 7, 2012.

5. US Department of Health and Human Services, National Health Service Corps. Mission and history. Available from: http://nhsc.hrsa.gov/corpsexperience/ aboutus/missionhistory/. Accessed May 7, 2012.

6. Politzer RM, Trible LQ, Robinson TD, et al. The National Health Service Corps for the 21st century. J Ambul Care Manage 2000;23:70-85.

7. US Department of Health and Human Services, Health Resources and Services Administration. Fiscal year 2008 annual performance report.

8. National Advisory Council of the National Health Service Corps. Priorities for reauthorization and legislative updates. March 2007. Available at: http:// nhsc.hrsa.gov/downloads/priorites.pdf. Accessed July 25, 2012.

9. US Department of Health and Human Services, Health Resources and Services Administration. Shortage designations: health professional shortage areas and medically underserved areas/populations. Available at: http://bhpr.hrsa.gov/shortage/. Accessed May 7, 2012.

10. Primary Care Workforce Act of 1993 (HR 2804). 103rd Congress, 1st session (1993); Section 6.

11. Mullan F. The muscular Samaritan: the National Health Service Corps in the new century. Health Aff (Millwood) 1999;18:168-75.

12. National Advisory Council of the National Health Service Corps. A National Health Service Corps for the 21st century. January 2000. Available from: http://nhsc.hrsa.gov/downloads/servicecorps.pdf. Accessed May 7, 2012.

13. American Recovery and Reinvestment Act of 2009 (HR 1). 111th Congress, 1st session (2009).

14. US Department of Health and Human Services, American Recovery and Reinvestment Act, Community Healthcare Services. Health Resources and Services Administration: health professions training programs-National Health Service Corps. Available from: http://www.hhs.gov/recovery/reports/plans/ pdf20100610/HRSA\%20National\% 20Health \% 20 Service\%20Corps\%20June\%202010.pdf. Accessed May 7, 2012.

15. Kaiser Commission on Medicaid and the Uninsured. American Recovery and Reinvestment Act (ARRA): Medicaid and health care provisions. Washington, DC: Henry J Kaiser Family Foundation; 2009. Available from: http://www.kff.org/medicaid/upload/7872. pdf. Accessed May 7, 2012. 
16. Spitzgo R. NHSC and health centers. Together making a difference. TA conference call. May 17, 2010. Available at: www.mphca.com/Literature Retrieve.aspx?ID=60265. Accessed May 7, 2012.

17. Pathman DE, Crouse BJ, Padilla LF, Horvath TV, Nguyen TT. American Recovery and Reinvestment Act and the expansion and strengthening of the $\mathrm{Na}$ tional Health Service Corps: a great opportunity for service-minded family physicians. J Am Board Fam Med 2009;22:582-4.

18. US Department of Health and Human Services, Grants.gov. ARRA-state primary care offices. Available from: http://www.grants.gov/search/search. do? mode $=$ VIEW\&oppId $=48808$. Accessed April 21, 2011.

19. US Department of Health and Human Services. News release. Affordable Care Act bolsters the primary care workforce in medically underserved communities. November 22, 2012. Available at: http:// www.hhs.gov/news/press/2010pres/11/20101122b.html. Accessed May 7, 2012.

20. Patient Protection and Affordable Care Act of 2010, Public Law 111-148, 11th Congress (2010).

21. WWAMI Rural Health Research Center. RUCA data version 2.0. Available from: http://depts. washington.edu/uwruca/ruca-data.php. Accessed May 7, 2012.

22. US Department of Agriculture, Economic Research Service. Rural-urban commuting area codes. Available from: http://www.ers.usda.gov/data-products/ rural-urban-commuting-area-codes.aspx. Accessed May 7, 2012.

23. Bishaw A, Macartney S. Poverty: 2008 and 2009. American community survey briefs. September 2010. Available from: http://www.census.gov/prod/ 2010pubs/acsbr09-1.pdf. Accessed May 7, 2012.

24. US Department of Health and Human Services. Key facts about the National Health Services Corps (NHSC). Available from: http://www.hhs. gov/recovery/programs/nhsc/nhscfactsheet.html. Accessed May 7, 2012.

25. Deleted in proof.

26. Association of the American Medical Colleges. Fiscal year 2012 National Health Services Corps. Available from: https://www.aamc.org/advocacy/meded/nhsc/ 176378/fy_2012_national_health_service_corps_nhsc. html. Accessed May 10, 2011.

27. US Department of Health and Human Services, Health Resources and Services Administration. National Advisory Council. Available from: http:// nhsc.hrsa.gov/about/nac.htm. Accessed May 10, 2011.
28. 3RNet. Medical school loan repayment programs: a brief summary. Available from: https://www.3rnet. org/aboutus/loanrepayment.aspx. Accessed May 7, 2012.

29. National Association of Community Health Centers. Health centers and health care reform: National Health Service Corps. Available from: http://www. nachc.org/client/Health\%20Reform \% 20Fact $\% 20$ Sheet\%20-\%20NHSC\%20Final2.pdf. Accessed July 25, 2012.

30. US Department of Health and Human Services, National Health Service Corps. Meeting summaries. May 20-22, 2010, meeting: Bethesda executive summary, Bethesda, Maryland. Available from: http:// nhsc.hrsa.gov/about/meetings/052010sum.htm. Accessed June 1, 2011.

31. Rosenblatt RA, Andrilla CHA, Curtin T, Hart LG. Shortages of medical personnel at community health centers. JAMA 2006;295:1042-9.

32. Alaska Health Planning and Systems Development. Information for practitioners. Available from: http:// www.hss.state.ak.us/dph/healthplanning/sharp/ practitioners.htm. Accessed May 7, 2012.

33. Tennessee Academy of Family Physicians. Tennessee State loan repayment program (TSLRP). Available from: http://www.tnafp.org/TNStateLoan RepaymentProgram.html. Accessed May 7, 2012.

34. US Department of Health and Human Services, Health Resources and Services Administration Data Warehouse. National Health Service Corps (NHSC) current provider FTE summary by state report. Available from: http://ersrs.hrsa.gov/ReportServer?/ HGDW_Reports/BCD_NHSC/BCD_NHSC_ FTE_State_Summary\&rs:Format=HTML3.2. Accessed May 13, 2011.

35. US Department of Health and Human Services, Health Resources and Services Administration Geospatial Data Warehouse. National Health Service Corps (NHSC). Available from: http://data warehouse.hrsa.gov/nhscdetail.aspx. Accessed June 8, 2009.

36. US Department of Health and Human Services, Health Resources and Services Administration. Fiscal year 2012 online performance appendix. Available from: http://www.hrsa.gov/about/budget/ performanceappendix2012.pdf. Accessed April 27, 2011.

37. US Department of Health and Human Services, National Health Service Corps. Loan repayment. Available from: http://nhsc.hrsa.gov/loanrepayment/. Accessed May 7, 2012. 